\title{
Spawning stock biomass modulation of environment - recruitment relationship in a marginal spring spawning herring (Clupea harengus membras) population
}

Ojaveer, Henn; Klais-Peets, Riina; Einberg, Heli; Rubene, Gunta

Published in:

Canadian Journal of Fisheries and Aquatic Sciences

Link to article, DOI:

10.1139/cjfas-2021-0018

Publication date:

2021

Document Version

Peer reviewed version

Link back to DTU Orbit

Citation (APA):

Ojaveer, H., Klais-Peets, R., Einberg, H., \& Rubene, G. (2021). Spawning stock biomass modulation of environment - recruitment relationship in a marginal spring spawning herring (Clupea harengus membras) population. Canadian Journal of Fisheries and Aquatic Sciences, 78(12), 1805-1815.

https://doi.org/10.1139/cjfas-2021-0018

\section{General rights}

Copyright and moral rights for the publications made accessible in the public portal are retained by the authors and/or other copyright owners and it is a condition of accessing publications that users recognise and abide by the legal requirements associated with these rights.

- Users may download and print one copy of any publication from the public portal for the purpose of private study or research.

- You may not further distribute the material or use it for any profit-making activity or commercial gain

- You may freely distribute the URL identifying the publication in the public portal 
1 Spawning stock biomass modulation of environment - recruitment relationship in a

2 marginal spring spawning herring (Clupea harengus membras) population

3 Henn Ojaveer ${ }^{1,2}$, Riina Klais-Peets ${ }^{3}$, Heli Einberg ${ }^{4}$ and Gunta Rubene ${ }^{5}$

$4 \quad{ }^{1}$ Pärnu College, University of Tartu, Ringi 35, 80012 Pärnu, Estonia

$5 \quad{ }^{2}$ National Institute of Aquatic Resources, Technical University of Denmark, Kemitorvet

$6 \quad$ Building 201, 2800 Kgs. Lyngby, Denmark

$7 \quad{ }^{3}$ EcoStat Ltd, Ladva 6, Tartu 50705, Estonia

$8{ }^{4}$ Estonian Marine Institute, University of Tartu, Mäealuse 14, 12618 Tallinn, Estonia

$9 \quad{ }^{5}$ Fish Resources Research Department, Institute of Food Safety, Animal Health and

10 Environment, Daugavgrivas 8, Riga LV-1048, Latvia

12 Corresponding author: Henn Ojaveer (email: henn.ojaveer@ut.ee). 


\section{Abstract}

15 Scientific interest in the dynamics of fish recruitment dates back to the beginning of the 20th

16 century. Since then, several studies have shown that the environment may have a stronger effect

17 on recruitment $(\mathrm{R})$ compared to that of the spawning stock biomass (SSB). By combining a suite

18 of methods designed to detect the non-linear, non-stationary and interactive relationships, we have

19 re-evaluated the potential drivers and their interactions responsible for the multiannual dynamics

20 of the recruitment dynamics of the Gulf of Riga (Baltic Sea) spring spawning herring population

21 at the longest time-span to date (1958-2015) allowing coverage of variable ecosystem conditions.

22 R was affected significantly by prey density and the severity of the first winter. Although SSB was

23 not a good predictor of R, adding interaction with SSB significantly improved the model, hence

24 the effect of the two environmental variables on R was modulated by SSB. While temporal changes

25 in the environment-R relationship were generally gradual, several abrupt changes were evident in

26 the strength of these relationships. In addition, non-stationary, linear and non-linear relationships

27 were observed.

28 Keywords: Baltic Sea, copepod abundance, long-term dynamics, linear and non-linear non-

29 stationary relationships, winter severity

\section{Introduction}

31 Scientific interest in the dynamics of the fish recruitment dates back to at least the beginning of

32 the 20th century, when it was understood that variations in catches are related to variations in

33 recruitment: “...These results naturally lead us to enquire into the causes, or better, the natural

34 phenomena which occasion these peculiar fluctuations in the renewal of the stock; the

35 hydrographical or biological conditions which give rise to the occurrence of rich or poor year 
36 classes of fish. The problem is one of unquestionable difficulty, embracing as it does all the

37 conditions which in any way affect the fish from the egg stage to the time when they are caught. It

38 will therefore appear most probable that the renewal of the fish stock, as in the case of any stock

39 on land, is dependent upon many factors, all necessary, and all more or less variable (Hjort 1914).

40 There is a strong theoretical and empirical basis for links between the biomass of spawning adults

41 and the number of young fish entering a population. For example, Myers and Barrowman (1996)

42 showed in meta-analyses that stocks with below - average spawning stock biomass (SSB) tended

43 to have lower-than-average recruitment (R) and vice versa. However, the effect of SSB on R

44 weakens as SSB increases in size, with R varying only weakly with SSB at large stock sizes (Ricker

45 1954; Beverton and Holt 1957), indicating that other factors, including environmental conditions

46 in the ecosystem, are key drivers for R at high stock size. The strong influence of environmental

47 conditions on R has been documented in several recent studies. For example, SSB explained only

48 up to $15 \%$ of the variability in R (Cury et al. 2014), and R and SSB were not positively related in

$4961 \%$ of 224 stocks in the global RAM Legacy Stock Assessment Database (Szuwalski et al. 2015).

50 Factors affecting $\mathrm{R}$ include parental effects (SSB size and age structure, fecundity, skipped

51 spawning, maternal effects), environmental factors (predation, starvation, oceanographic

52 condition) and direct human intervention - fishing (Bailey et al. 2005, and references therein).

53 Moreover, there are studies to demonstrate that interactions between SSB and environmental

54 conditions can affect R (e.g., Brander 2010; Perry et al. 2010). Thus, both biotic and abiotic factors

55 and their interaction need to be investigated when attempting to understand the causes of $\mathrm{R}$

56 variability (Myers 1998; Perry et al. 2010). 
57 Several studies have shown that inclusion of environmental variables significantly contributed to

58 improved predictability of R (e.g., Stige et al. 2013) and that the dynamics of exploited stocks can

59 be described better if environmental or climatic variability is incorporated in the recruitment

60 models (Keyl and Wolff 2008). The ability to detect the effect of environmental forcing on R

61 inevitably increases with the length of the time series, especially when already encompassing

62 multiple cycles of an environmental index (Haltuch and Punt 2011). However, the environment-R

63 relationships of a given stock may change over time (Myers 1998), due to several reasons, such as

64 non-stationarity (Stige et al. 2006; Ottersen et al. 2013), non-linearity (Beggs et al. 2014), changes

65 in population age structure, reproductive potential or spatial heterogeneity of the underlying

66 processes (Keyl and Wolff 2008). As a result, empirical case studies often result in increasingly

67 unclear relationships the longer the time series become. Therefore, despite the assumed virtue,

68 longer time series also pose new methodological challenges to the ability to predict $\mathrm{R}$ from

69 environmental factors, including the incorporation of temporal changes itself into the models.

70 Evidence of temporal changes in environment-R relationship spans over different species/stocks

71 and ecosystems. For example, the positive correlation between the recruitment of Northeast Arctic

72 haddock and cod, and North Atlantic Oscillation index in 1973-1996 disappeared when extending

73 the time-series back in time to 1945 (Solow 2002). Also, the strength of correlations of the

74 environment-R relationship of several fish stocks in the Barents Sea, Gulf of Alaska and Bering

75 Sea evidenced substantial variations over multidecadal scales with the relationship in some stocks

76 reversing sign (Stige et al. 2013).

77 Herring populations commonly experience collapses and recoveries, which directly influence

78 herring fisheries and have direct implications for national economies (e.g., Sigurdsson 2006). 
79 Investigations of 64 herring populations detected the importance of local drivers in formation of

$80 \mathrm{R}$ and suggested that generally complex and uncertain processes are responsible for the

81 relationship between SSB and R (Trochta et al. 2020). One of the important drivers behind herring

82 dynamics is climate change/warming, operating via modifications in ecosystem conditions, which

83 may affect larval drift or cause changes in growth rates and recruitment survival (Drinkwater and

84 Kristiansen 2018; Tiedemann et al. 2020).

85 Herring has been one of the most important commercial fish species in the Baltic Sea for centuries.

86 Investigations in the environmental effects on spring spawning herring (Clupea harengus

87 membras) were initiated in the Baltic Sea already at the end of the 1940s with the ultimate objective

88 to identify environmental factors suitable for forecasting R (Rannak 1971, and references therein).

89 These early and following investigations have identified several abiotic and biotic environmental

90 factors, together with suggested processes/mechanisms responsible, that influence spring

91 spawning herring $\mathrm{R}$ during different time-periods facing different ecosystem conditions. Also,

92 these investigations have formed a base for establishment and maintaining continuous long-term

93 time-series on several hydroclimate and environmental parameters. The aim of the current paper

94 was to re-evaluate these potential drivers and their interactions responsible for the multiannual

95 dynamics of the Gulf of Riga (GoR) spring spawning herring R. We used the data covering the

96 longest time span to date (1958-2015), and a suite of methods designed to detect the non-linear,

97 non-stationary and state-dependent links between $\mathrm{R}$ and its drivers, and more realistic criteria for

98 model performance than simple explanatory power (e.g., out of sample prediction skill).

99 Material and Methods

100

\section{The study area and the population}


101 The GoR is a shallow (mean depth $27 \mathrm{~m}$ ) partly landlocked sub-basin in the Baltic Sea, separated

102 from the Baltic Proper by the shallow and narrow Irbe Strait. In most parts, salinity ranges between

1035.0 and 6.5 PSU with the absence of a permanent halocline (Kotta et al. 2008). Due to its

104 shallowness, the changes in air temperature have a direct influence on the dynamics of the

105 temperature regime of the GoR (Kotta et al. 2009). Due to strong vertical mixing, dissolved oxygen

106 concentration is in most areas higher than $5 \mathrm{~mL} \mathrm{~L}^{-1}$, while below $2 \mathrm{~mL} \mathrm{~L}^{-1}$ values have occasionally

107 been found in the deepest part of the GoR (>45 m; Kotta et al. 2008).

108 The GoR spring spawning herring represents a small population with a current stock size of ca.

109 160-190 thousand tons and annual landings around 26-33 thousand tons (ICES 2020). The fish

110 does not undergo major migrations into the open Baltic Sea (only a minor component of the older

111 herring may leave the GoR during summer/autumn), and constitutes thus a local resident

112 population managed as a separate stock (ICES 2020). Compared to the other spring spawning

113 herring stocks of the Baltic Sea, the GoR spring spawning herring is characterized by the lowest

114 mean weight-at-age values: the mean individual weight of age groups 1-8 of the GoR herring and

115 other herring stocks of the Baltic Sea in 2019 were 19.9 and 22.4-31.1 g, respectively (ICES 2020).

\section{Data sources and preparation of time series}

117 Annual data on R and SSB of the GoR spring spawning herring originate from Ojaveer et al. (2004)

118 and ICES (2020), data from 1958 to 2015 was used. $\mathrm{R}$ is reported for the year when fish are already

119 one year old. However, the first year of life is the most critical for survival of herring (i.e.,

120 determines the recruitment abundance) and the key processes may actually occur during the first

121 months of life (e.g., Oeberst et al. 2009; Payne et al. 2009). Therefore, for the purpose of current 
122 analysis, we shifted the time series of $\mathrm{R}$ by one year earlier, to align it with the environmental

123 conditions and SSB values corresponding to the first year of life.

124 Daily air temperatures, measured at Kihnu weather station (58.09861 N, 23.97028 E), were

125 provided by Estonian Environment Agency. Winter severity was calculated as a sum of negative

126 daily mean air temperatures from November to March (e.g., Radziejewska and Chabior 2004;

127 Livdane et al. 2016), and assigned to the year of spring (e.g., 1990 winter severity describes the

128 period from November 1989 - April 1990). Winter severity was included in analyses in two

129 versions: original and lagged. Original series describes the winter before hatching (WS0) and the

130 lagged series the first winter these individuals survived (WS1).

131 The mean water temperature of 0-20 m water layer in May has previously been identified as a

132 reasonably good predictor of the GoR spring spawning herring R dynamics (ICES 2020).

133 Unfortunately, the in situ temperature measurements have been available only since 1963. As there

134 is empirical evidence on the close correlation between the sea surface temperature (SST) in the

135 GoR and the air temperature measured in a nearby hydrometeorological station $\left(\mathrm{r}^{2}>0.90\right.$; Kotta

136 et al. 2009), we used the mean daily air temperatures in May instead. We hereby also argue that

137 consistently and frequently (hourly) recorded air temperature data is likely a more reliable proxy

138 of long-term (interannual) variability of the temperature conditions than irregularly sampled in situ

139 water temperatures.

140 Diet of various life stages of the GoR spring spawning herring has been extensively studied, with

141 the evidence originating from different decades. From these studies, the copepod Eurytemora

142 affinis clearly appears the preferred and dominating prey for larvae (Arula et al. 2012), and 143 juveniles and adults (Ojaveer et al. 2017 and references therein). Therefore, density of E. affinis 
144 was used as a proxy for describing the prey availability. Abundance data of E. affinis was extracted 145 from the Baltic Sea zooplankton database (Klais et al. 2016), obtained from the Institute of Food 146 and Safety, Animal Health and Environment (BIOR, Latvia) and Estonian Marine Institute, 147 University of Tartu (Estonia). From the open GoR, samples were collected during spring (May) 148 monitoring cruises covering the entire basin, with vertical tows of a Juday net (mesh size $160 \mu \mathrm{m}$, 149 opening diameter of upper ring $36 \mathrm{~cm}$ ) and fixed in 4\% formaldehyde solution. From Pärnu Bay, 150 sampling was seasonally more frequent, and we used the data from the samples collected in May 151 and June. Sample collection and analysis procedure was based on UNESCO (1968) and remained 152 the same throughout the survey period.

153 From the E. affinis abundance data, three annual time series were calculated for both open GoR 154 and Pärnu Bay, aggregating three different stages: 1) copepodites I-III, 2) copepodites IV-V, and 155 3) adult copepods. The abundances were converted from the volumetric unit (ind. $\mathrm{x} \mathrm{m}^{-3}$ ) to area 156 units (ind. $\mathrm{x} \mathrm{m}^{-2}$ ), using the depth of the sampled profile. Since the spatio-temporal coverage of 157 zooplankton data was not exactly the same every year, the annual values were estimated with the 158 generalized additive model (GAM) (Wood 2017), where the sampling year was included as a 159 categorical variable, in addition to the smooth functions of day of year (to account for the 160 differences in exact timing of the cruise), and latitude and longitude as tensor product (two161 dimensional smooth, to account for variations in exact locations of samples between years). 162 Annual values were predicted by this model at the mid-points of latitude and longitude and the 163 mean day of year, thereby assuring the comparability of annual values in spite of variations in the 164 actual sampling scheme.

\section{Statistical modelling}


166 We first used GAM in a forward selection procedure to find the combination of variables that 167 explain best the variability in $\mathrm{R}$, while also testing for the non-linear links between $\mathrm{R}$ and the 168 selected variables. Akaike's Information Criterion (AIC), adjusted $\mathrm{R}^{2}$, and significance (p-value) 169 of added terms was used to guide the forward selection procedure. Two types of models were used: 170 in the first model, all variables (except SSB) were included as individual smooth terms, in the 171 second model, all variables (except SSB) were included as tensor products (two-dimensional 172 smooth functions), where the second axis was always SSB.

173 Out of sample prediction skill was used as an additional measure of the model performance, and 174 it was estimated for all GAM models that were fitted in the previous step, including all steps of 175 the forward selection procedure. Due to small sample volume, a leave-one-out cross-validation 176 (2011) approach was selected, i.e., the same model was fitted 55 times, excluding each year once, 177 and predicting with the model the $\mathrm{R}$ to the year excluded from the model training data. The skill 178 is measured as the adjusted $\mathrm{R}^{2}$ of a linear model: observed $\mathrm{R} \sim$ predicted $\mathrm{R}$. This method can be 179 used to evaluate which model has the most potential to predict "future" R.

180 The most optimal degrees of freedom for the smooth terms were estimated by varying $\mathrm{k}$ values

181 between 3...6, and choosing the $\mathrm{k}$ that yielded the lowest GCV (Generalized Cross Validation) 182 score. Concurvity (generalization of collinearity) between explanatory variables, where some 183 smooth term in a model could be approximated by one or more of the other smooth terms in the 184 model, is also a potential issue for GAM models, and can make the estimates unstable. Therefore, 185 a concurvity test was applied to the final models and reported.

\section{Temporal changes in the environment - recruitment relationship}


187 Temporal behavior of the links between $\mathrm{R}$ and the explanatory variables from final GAMs (M1 188 and M2) were also analysed individually using two approaches: a growing window analysis, and 189 sliding window analysis. In the growing window analysis, univariate GAMs were fitted to the 190 gradually growing subsets of data, starting with the first 20 years, and then adding 1 year at each 191 step. Goal of this approach was to mimic the real-world situation where time series are gradually 192 growing, and often the links observed at first, disappear or change. Sliding window analysis was 193 used to detect and visualize the non-stationarity in the links between R and the selected explanatory 194 variables, similar to Kirby and Beaugrand (2009). This approach calculates the linear model 195 parameters (slope, and p-value) for moving time periods (15 years window) with an increment of 196 one year.

197 All analyses and visualisations were done in RStudio (version 1.3.1056, using $R$ 4.0.2), GAM 198 models were fitted using the library $m g c v(1.8-31)$. Aim of the analysis is brought out in Table 1.

199 Results

200 The multi-decadal dynamics of herring stock characteristics, and of the variables that were 201 determined as significant drivers of the $\mathrm{R}$ in later steps of analysis: the copepodites IV-V in open

202 GoR, and the severity of the first winter the fish survived, are displayed in Fig. 1. Dynamics of all 203 other explanatory variables used in the modelling, which didn't qualify as significant drivers (mean 204 May air temperature; abundance of E. affinis copepodites stages I-III and adult copepodites in the 205 open GoR; and abundance of E. affinis copepodites stages I-III, IV-V and adult copepodites in 206 Pärnu Bay) are shown in supplementary Fig. S1. Herring R and SSB show generally similar 207 patterns over the whole study period by exhibiting notably higher values since the early 1990 s. 208 SSB remained generally below 50 thousand tons before the late 1980s, but often exceeded 100 
209 tons level since then. Increase in R was less pronounced than that of SSB, but R became more

210 variable after the early 1990s (Fig. 1a). Except for a few years, the abundance of E. affinis

211 copepodites stages IV-V in the open GoR remained below 200000 ind. $\mathrm{m}^{-2}$, but exhibited a few

212 peaks with values above 500000 ind. $\mathrm{m}^{-2}$ (Fig. 1b). Abundance of E. affinis has generally shown

213 an increase since the end of the 1970s and has remained at a higher level starting from 1990. In

214 general, winters have become milder over time. The period until the mid 1980s is characterised

215 with high variability in winter severity and several extremely low values. In contrast, many

216 consecutive very mild winters have been observed since the end 1980 with the coldest winters

217 being always warmer than until the mid-1980s (Fig. 1c).

218 The final model of GAM without interaction to SSB included the open GoR prey abundance $(E$.

219 affinis; copepodite stages IV-V) and winter severity of the first year of life (WS1) (adjusted R²:

$220 \quad 0.52, \mathrm{p}<0.05$; Table $2, \mathrm{M} 1)$ as the best predictors of interannual variability in $\mathrm{R}$. While R increased

221 with prey abundance linearly (Fig. 2a), the relationship with winter severity was unimodal, with a

222 peak at average winter temperatures and lower R for both, very mild and harsh winters (Fig. 2b).

223 Concurvity index was 0.12 for prey and 0.11 for winter severity, indicating that both terms

224 contributed to the model orthogonally.

225 The final model of GAM with interaction to SSB included the same variables as the previous

226 model, but the overall explanatory power of the model was higher (adjusted $\mathrm{R}^{2}: 0.62, \mathrm{p}<0.001$;

227 Table 2, M2). Highest values of R coincided with high levels of SSB combined with high prey 228 abundance (Fig. 3a). In addition, elevated levels of R were detected in combination with low SSB 229 and average winter temperatures (Fig. 3b). Concurvity tests indicated relatively high correlation 
230 between the terms (0.44-0.51), which was expected given that the SSB was included in both 231 interactions.

232 Out of the sample prediction skill test evaluated the potential of different GAM model candidates 233 (steps 1 and 2 of M1 and M2; Table 2) to predict the future R values, and the results of this analysis 234 allowed us to make two main observations. First, all M2 model steps where explanatory variables 235 included an interaction with SSB, showed higher prediction skill than any of the M1 model steps.

236 Second, winter severity improved the models' prediction skill only when it was in interaction with 237 SSB (i.e., M1 step 1, the prey alone had as high adjusted $\mathrm{R}^{2}$ as the step 2, but in M2, the adjusted $238 \mathrm{R}^{2}$ increased still notably when adding the te(SSB, winter severity (WS1)) to the model; Table 2; 239 Fig. 4). The improved prediction skill of M2 over M1 is visually evident from better match between 240 the observed and predicted values, particularly for the period since the early 1990s, characterised 241 by higher variability of R (Fig. 4).

242 Growing window analysis was applied to test if the shape of the link, direction or the strength of 243 it between $\mathrm{R}$ and the investigated variables changes in relation to the length of the time-series. The 244 relationship between R and SSB appeared to be unimodal during about the first 25 years peaking 245 at around 30-40 thousand tons of SSB. When the time series was further extended, the unimodal 246 relationship was quite abruptly replaced with a more linear and positive relationship between $\mathrm{R}$ 247 and SSB (Fig. 5a), coinciding with about two-fold increase in the adjusted $\mathrm{R}^{2}$ (from around 0.15 248 to 0.30 , Fig. 5b). Addition of the last 5 years to the time series (i.e., 2010-2015), revealed a new 249 maximum of $\mathrm{R}$ at high SSB level (ca. 90 thousand tons). The relationship between $\mathrm{R}$ and the prey 250 abundance becomes more linear and more positive with every added year, adjusted $\mathrm{R}^{2}$ value was 251 low during the first three decades, but much higher since then, exceeding 0.45 mostly (Fig. 5c, d). 
252 Winter severity, in contrast, has only a very marginal effect on $\mathrm{R}$, at least when it is considered as 253 a single variable in the model (Fig. 5e, f).

254 The sliding window analysis was applied to test the changes in strength and direction of the linear 255 relationship between $\mathrm{R}$ and the investigated variables over time, while looking at the moving fixed 256 length (15 year) time window. With exception in the 1970s, the relationship with SSB was positive

257 from the beginning of the time-series until the mid-1990s, with a few most positive and significant 258 relationships recorded for the $\mathrm{mid} / \mathrm{second}-$ half of the 1980s. The relationship gradually declined 259 since the peak values and remained negative until recently (Fig. 6a, b). The relationship between 260 R and prey abundance has been always positive, and in most cases also significant, with gradual

261 increase of the slope since the 1980s (Fig. 6c, d). The relationship between R and winter severity 262 (WS1) has been mostly negative and insignificant throughout the entire period, except the 1980s, 263 followed by a gradual sharp decrease to the early 2010s (Fig. 6e, f).

\section{Discussion}

265 What affects the R dynamics of commercial fish has a long history of research, but still remains 266 as one of the most prominent questions in contemporary fisheries science (e.g., Somarakis et al. 267 2019). Myers and Barrowman (1996) showed that low SSB results in low R. However, low SSB 268 and low R can be explained equally well by low R generating low SSB (Szuwalski et al. 2015). 269 Extension of the length of time-series, into ecosystem conditions likely not met before, offers new 270 avenues, including incorporation of environmental effects. While $\mathrm{R}$ dynamics is regulated by the 271 interaction of multiple drivers (e.g., Wilson et al. 2018), and are therefore generally challenging to 272 assess or predict because of the variation in their relevance over time and space, combining 273 different data analysis techniques can be useful in improving our understanding in this matter 
274 (Zimmermann et al. 2019). Through the utilization of different numerical and data visualization

275 tools, we were able to identify the most likely drivers behind the long-term R dynamics of the GoR

276 spring spawning herring population, together with specifying the patterns and types of the links

277 between the suggested drivers and $\mathrm{R}$.

278 Factors affecting GoR spring spawning herring $\mathrm{R}$ have been investigated since the 1950s. These

279 investigations have been performed at shorter time-periods with applying simpler and fewer

280 methodological approaches simultaneously than in the current work. In previous studies, variables

281 identified as significant predictors of $\mathrm{R}$ included the abundance of food during the larval seasonal

282 maximum in coastal areas (during 1961-1973; Rannak and Simm 1979), Fulton condition factor

283 of age groups 2-5 (1977-2010; Putnis et al. 2011), strength of westerly winds in winter, winter air

284 temperature and SST in April (1952-1970; Ojaveer 1974), Baltic Sea Index in winter, SST and

285 SSB (1977-2004; Cardinale et al. 2009; Margonski et al. 2010), larval abundance in coastal areas,

286 winter air temperature, and SSB during the mild winters (1951-2004; Ojaveer et al. 2011). Re-

287 evaluation of all driver candidates from this list was impossible due to methodological constraints

288 to data availability, but some comparisons of earlier results can be made. From the range of drivers

289 analysed, R appeared to be driven most consistently by prey density in the open GoR, and the

290 severity of the first winter the individuals survived. This finding corroborates the previous general

291 suggestion by Raid et al. (2010) that the environment may be the key in defining R abundance,

292 now substantiated with data. Although SSB itself was not a good predictor of R, adding interaction

293 with SSB to other significant terms improved the overall model power significantly, hence their

294 effect was modulated by the level of SSB. The significantly stronger link between R and the open

295 GoR prey, compared to the effect of prey in coastal areas, corrects earlier studies stressing the key

296 role of coastal nursery areas for the survival of larvae (Rannak and Simm 1979), and implies even 

stronger role of larger scale processes affecting the R abundance. SSB no longer qualified as a 298 significant driver for R dynamics during the period of mild winters, as suggested previously by 299 Ojaveer et al. (2011). Several mild winters have occurred since the ecosystem regime shift during $3001988 / 1989$. The impact of SSB on R during this period was only marginal, with SSB being very 301 often negatively linked to R.

302 Stock-recruitment relationships fail to capture the variation in $\mathrm{R}$, due to the multiple drivers of $\mathrm{R}$ 303 dynamics, including predation on early life stages (Zimmermann et al. 2021) which is a major 304 factor controlling R success of marine fish stocks (e.g., Bailey and Houde 1989). For example, the 305 top-down control of the herring larval stage by Atlantic mackerel (Scomber scombrus) has been 306 most recently identified as one of the two main processes to control the $\mathrm{R}$ of the Norwegian spring 307 spawning herring (Garcia et al. 2021). There is also evidence of intense predation on cod eggs by 308 herring and sprat in the Baltic Sea which may affect R of the eastern Baltic cod stock (Köster et 309 al. 2017, and references therein). However, based on the evidence so far, predation on early life 310 stages has not been identified as a likely driver affecting herring $\mathrm{R}$ in the GoR, as the share of 311 herring eggs and larvae in stomachs of most abundant local species (such as pikeperch Sander 312 lucioperca, three spined stickleback Gasterosteus aculeatus, smelt Osmerus eperlanus and sprat 313 Sprattus sprattus) is either low or negligible (Ojaveer et al. 1997).

314 It has been suggested that SSB may not be a good indicator of reproductive potential of a stock 315 (Walters and Ludwig 1981), and the spawning potential of the repeat spawners should be used 316 instead (Oskarsson and Taggart 2010). In addition, skipped spawning (Bucholz et al. 2013), size317 dependent fecundity (Le Bris et al. 2015), size-dependent total reproductive-energy output of 318 females (Barneche et al. 2018) and fish condition-dependent fecundity (Marshall et al. 1998; dos 
319 Santos Schmidt et al. 2017) need to be considered in reproductive potential estimates. Although

320 we do possess some information and knowledge on these issues for the GoR spring spawning

321 herring (e.g., Fulton condition factor, size-dependent individual fecundity and population

322 fecundity), relevant time series at the scale of the current study are lacking (Raid et al. 2010; Putnis

323 et al. 2011). As a result, failure in incorporating this information weakens the 'power' of SSB as

324 an accurate predictor of the reproductive potential.

\section{Non-stationary and non-linear effects in GoR herring recruitment dynamics}

326 The number of studies have shown that the relationships in natural ecosystems are often non-linear

327 and non-stationary, due to simultaneous changes in multiple relevant drivers, and that exploited

328 species are more likely to display abrupt changes than unexploited species (Glaser et al. 2014). For

329 example, in variation of the relationship between R, SSB and temperature of the 38 commercially

330 harvested fish stocks in the northern North Atlantic stocks, threshold models performed better than

331 the linear or non-linear stationary models for 27 stocks, suggesting that abrupt changes are

332 common (Ottersen et al. 2013). Another example is decoupling of herring growth from hydro-

333 climatic factors above a certain threshold abundance of sprat in the Baltic Sea (Casini et al. 2010).

334 The transient nature of the drivers of GoR spring spawning herring $\mathrm{R}$ was manifested in several

335 observations in this study, including sudden changes in the strength of the effects over time,

336 gradual changes in the type of the links, and the state dependence.

337 Extending the time-series may not only result in changes in the links of the R - explanatory

338 variables relationship (Ottersen et al. 2013), but also the strength of the relationship (Stige et al.

339 2013). While the relationships between $\mathrm{R}$ and environment changed generally gradually, rapid

340 changes were observed in the strength of these relationships in both, the growing and sliding 
341 window analyses (adj. $\mathrm{R}^{2}$ of each step). Most dramatic changes, in the form of sudden increase in

342 explanatory power in sliding window analysis, were found in the beginning of 1980s, in the effect

343 of SSB and prey density on R. These changes coincided with a gradual (in case of prey density) or

344 more rapid (SSB) increase in the relationship with R (i.e., slope of the linear model).

345 Also, the type of the relationships between $\mathrm{R}$ and the investigated three explanatory variables

346 changed throughout the time-series, most prominently in the case of R $v s$ SSB: from unimodal to

347 linear to a new unimodal, but with a shifted optimum. In the models of R vs winter severity, the

348 result of a growing time series was a change of the link from unimodal to linear, while significantly

349 losing the explanatory power at the same time. At least some of the observed patterns (from the

350 growing window and sliding window analysis) can be clearly related to climate-driven ecosystem

351 regime shift at the end of the 1980s, to a warmer and less saline conditions, which amongst others,

352 resulted in elevated abundances of small-size brackish copepods and very high clupeid biomasses

353 (e.g., Möllmann et al. 2000). The notable improvement of model performance when the interaction

354 with SSB was included in the effects of prey and winter severity is additional proof of the state-

355 dependence, in this case, depending on the level of SSB.

356 Another, less obvious example of a non-stationary (or even state-dependent) process was the type

357 of prey that seems to be critical for R. Evidence supporting the early life-stage regulation of year-

358 class strength in herring is common (e.g., Nash and Dickey-Collas 2005), possibly happening

359 already during the early larval stages (Oeberst et al. 2009), when prey availability plays a key

360 factor in the survival (e.g., Rannak and Simm 1979; Alvarez-Fernandez et al. 2015). The most

361 significant explanatory variable explaining the multiannual dynamics of GoR spring spawning

362 herring $\mathrm{R}$ was the abundance of the late copepodite stages (IV-V) of E. affinis, which used to be 
363 the main prey of large larvae (Arula et al. 2012), at least in the 1970s. This finding would imply

364 that critical regulation of spring spawning herring $\mathrm{R}$ occurs rather during the late larvae in the

365 GoR. However, the situation has probably changed over time. Water transparency in the GoR is

366 very low and has decreased even more during the past decades due to excessive eutrophication.

367 Reduced visibility can cause shifts in prey composition of larval herring, and force already

368 medium-sized larvae to feed on late copepodites (stages IV-V) in the 2000s, but not in the 1970s

369 (Arula et al. 2012). Thus, it is possible that some of the mechanisms responsible for the regulation

370 of herring $\mathrm{R}$ abundance are dependent on the change of habitat conditions over time.

371 Somewhat surprisingly, considering that herring in the Baltic Sea is situated at the limit of the

372 species' geographical range, and also in contrast to several previous studies, the climate signal 373 appeared to be relatively weak and mostly insignificant, manifested mainly via the winter severity

374 of the first year of life. Inclusion of winter severity increased the predictive power of the model,

375 but only in case the interaction with the food resource was introduced to the model before. The

376 unimodal link between $\mathrm{R}$ and winter severity further pointed to the existence of an optimum range

377 of winter severity for the recruitment success of GoR herring population. Nevertheless, it must be

378 noted that climate (winter air temperature and spring SST) significantly affects the dynamics of

379 the main prey of herring - E. affinis - via modulation of timing of annual reproductive processes

380 and abundance levels in the GoR (Kornilovs et al. 2004; Klais et al. 2017). Thus, climate is

381 indirectly affecting interannual abundance dynamics of R through food-web dynamics.

382 Overall, our results point to a dynamic nature of the relationship between $\mathrm{R}$ and explanatory 383 variables, and at minimum, call for caution in selecting either explanatory variables, time-periods 
384 or analytical methods for investigations in multiannual dynamics or recruitment abundance, and 385 interpreting and generalising the obtained results.

\section{Relevance of time scale in the functional understanding}

387 Time series of sufficient length are a prerequisite for unravelling the relative roles of different

388 factors affecting $\mathrm{R}$ and evaluating whether the same factors remain dominant over longer periods

389 (Hjort 1914). Ideally, the observation period should cover at least one prominent environmental

390 cycle, to allow the detection of non-linear or non-stationary links. Longer time series that

391 encompass multiple environmental cycles reduce the risk of finding spurious correlations (Haltuch

392 and Punt 2011). Thus, shorter time series can bias the identification of most important drivers of

393 R.

394 Many previous attempts to identify parameters affecting GoR spring spawning herring R dynamics

395 were based on relatively short time series (2-3 decades), and applying mostly linear or parametric

396 methods. Such studies were not even designed to detect non-stationary and non-linear links, like

397 the ones that were found here and also often suggested to be the most common kind in any

398 ecosystem. Current study was also based on the longest time series of GoR herring R to date. As

399 expected, we gained several new insights that contrast at least some of the earlier observations (see

400 above), and allow us to better understand the complexity of driving forces affecting the dynamics

401 of herring $\mathrm{R}$ at different ecosystem states. Despite covering time-period over five decades, the

402 evidence suggests that we haven't seen the entire cycle neither for environmental variables nor for

403 the herring population (i.e., closing the loop) yet. Therefore, continuation of data collection (not

404 only just for those parameters which appeared significant in the current work) would be required, 405 to re-evaluate the relationships again in the future. 
406 Our results further support the statement made in previous studies that multiple factors, rather than

407 a single driver, interact in the regulation of the herring year-class abundance. Failure to document

408 the significant relationship between the suggested drivers and $\mathrm{R}$ abundance may point to either

409 inappropriate sampling schemes or knowledge gaps in relevant drivers (Wilson et al. 2018). The

410 landscape of continuous improvement of our process-based knowledge, appearance of new

411 analytical methods, and modification of sampling schemes and data collection methodologies

412 poses challenges for identification of relevant drivers and selection of appropriate parameters to

413 be incorporated into the long-term studies at the temporal scale comparable to the current one.

414 While shorter time-scales allow analyses of higher numbers of different parameters, and so offer

415 new insights in the process-based relationships applicable for particular ecosystem states,

416 conclusions derived from the longer time series analyses, incorporating various ecosystem states,

417 are more robust. One of such relevant outcomes of the current study is the importance of SSB in

418 the modulation of the $\mathrm{R}$ vs winter severity relationship, where the effect of winter severity was

419 observed only at low levels of SSB.

420 Relevance for stock assessment and predictions

421 Although the ecosystem approach to fisheries management has formally been widely adopted at 422 least conceptually about 25 years ago, fish stock assessment and tactical management takes still 423 very little account of ecosystem processes, implicitly ignoring that fish stock production depends 424 on the physical and biological conditions of the ecosystem (Skern-Mauritzen et al. 2016). One of 425 the reasons lies in the limited ability to predict $\mathrm{R}$ from environmental factors even if the principal 426 mechanisms are understood (Myers 1998; Dickey-Collas et al. 2010). Thus, even if an 
427 environmental variable is important, it does not mean that it is key to the management of the 428 fishery.

429 Mean water temperature of 0-20 m water layer and the biomass of the main prey (the copepod $E$. 430 affinis) in May have in the past been good predictors of the R, and were used in the GoR herring 431 assessments and forecasts until 2011 (ICES 2020). When only the data after 2000 was used, 432 biomass of E. affinis in May, and Fulton's condition factor for ages 2-5 proved to be good 433 predictors of $\mathrm{R}$, however, incorporating these variables into the herring assessment models also 434 failed due to high variation ratio (ICES 2020). Thus, despite over 60 years of investigations, 435 environment-based forecasts are still less reliable than other approaches for the GoR spring 436 spawning herring assessment on regular basis, and the short-term forecast is currently based on 437 the geometric mean of year classes from 1989 corresponding to a period of improved reproduction 438 conditions and prevalence of mild winters (ICES 2020). The sliding window analysis in the current 439 study implies that the abundance of copepodite stages IV-V of E. affinis described fairly well 440 (small standard error) R dynamics until 1994 (incorporating years 1987-2011), but the standard 441 error of the relationship increased sharply since then and has remained high until the end of the 442 time-series. This increase is associated with the ecosystem-level regime shift which took place at 443 the end 1980s (Möllmann et al. 2000). Thus, the current ecosystem regime is characterised by a 444 still significant, but variable relationship between herring R and abundance of critical prey, which 445 might not be satisfactory for assessment purposes on a regular basis.

\section{$446 \quad$ Future work}

447 Shallow littoral habitat plays a key role for early life-stages of herring in the Baltic Sea (Polte et 448 al. 2017), supported by significant relationship between the larval abundance in the shallow coastal 
449 area in the GoR (Pärnu Bay) and spring spawning herring R, found for shorter time-periods than

450 considered in the current work (Ojaveer et al. 2011; Arula et al. 2016). Unfortunately, these

451 extensive high-frequency larval time-series did not meet the requirements to be incorporated into

452 the current analysis, because they are missing data for several years due to lack of surveys. Future

453 investigations should utilise alternative analytical approaches to quantify the importance of larval

454 abundance (by different developmental stages) on the GoR spring spawning herring population R.

455 Also, feasibility of applying the larval growth index approach, which takes into account the non-

456 linear relationship between water temperature and larval growth rate (Xing et al. 2021), should be

457 considered. Larval index might be a better proxy than other environmental parameters

458 (temperature or prey density) to study R dynamics and might allow incorporation of temporally

459 patchy data on herring larvae in R predictions. Overall, this may lead to new possibilities for

460 predicting $\mathrm{R}$ for routine assessment purposes.

461 Further progress in explaining R can also be achieved by using more sensitive measures of the true 462 reproductive potential of the stock than the SSB. To increase our understanding of the stock's

463 dynamics, consideration should be given to adaptive changes in the reproductive investment in 464 relation to the effects of environment and exploitation (Claireaux et al. 2020). There is rather good 465 data and information available for the stock (e.g., Raid et al. 2010, and references therein; ICES 466 2020), however, at a shorter time-period than covered by the current study (generally since the end 467 1970s).

\section{Acknowledgements}

469 The authors are very grateful to two anonymous reviewers for their very constructive critique that 470 substantially improved the quality of the manuscript. 


\section{Competing interests}

472 The authors declare there are no competing interests.

\section{Contributors' statement}

474 HO: Conceptualization, Funding acquisition, Investigation, Project administration, Supervision, 475 Writing - Original draft. RKP: Conceptualization, Data curation, Formal analysis, Investigation, 476 Methodology, Resources, Supervision, Writing - Original draft. HE: Data curation, Formal

477 analysis, Investigation, Visualization, Writing - Original draft. GR: Data curation, Investigation, 478 Writing - Review \& Editing.

\section{$479 \quad$ Funding statement}

480 This work resulted from the Joint Baltic Sea Research and Development Programme (BONUS) 481 project 'Taking stock of Baltic Sea food webs: synthesis for sustainable use of ecosystem goods 482 and services', XWEBS, which was supported by BONUS (Art 185), funded jointly by the 483 European Union, Estonian Research Council and Innovation Fund for Denmark.

\section{Data availability statement}

485 The data underpinning the work are available upon request.

\section{References}

487 Alvarez-Fernandez, S., Licandro, P., van Damme, C.J.G., and Hufnagl, M. 2015. Effect of 488 zooplankton on fish larval abundance and distribution: a long-term study of North Sea herring 489 (Clupea harengus). ICES J. Mar. Sci. 72(9): 2569-2577. doi:10.1093/icesjms/fsv140. 
Arula, T., Kotta, J., Lankov, A., Simm, M., and Põlme, S. 2012. Diet composition and feeding

491 activity of larval spring-spawning herring: importance of environmental variability. J. Sea Res.

492 68: 33-40. doi:10.1016/j.seares.2011.12.003.

493 Arula, T., Raid, T., Simm, M., and Ojaveer, H. 2016. Temperature-driven changes in early life-

494 history stages influence the Gulf of Riga spring spawning herring (Clupea harengus m.)

495 recruitment abundance. Hydrobiologia 767(1): 125-135. doi:10.1007/s10750-015-2486-8.

496 Bailey, K.M., Ciannelli, L., Bond, N.A., Belgrano, A., and Stenseth, N.C. 2005. Recruitment of 497 walleye pollock in a physically and biologically complex ecosystem: A new perspective. Prog. 498 Oceanogr. 67(1-2): 24-42. doi:10.1016/j.pocean.2005.06.001.

499 Bailey, K. M., and Houde, E. D. 1989. Predation on eggs and larvae of marine fishes and the 500 recruitment problem. Adv. Mar. 25: 1-83.

501 Barneche, D. R., Robertson, D. R., White, C. R., and Marshall, D. J. 2018 Fish reproductive502 energy output increases disproportionately with body size. Science. 360(6389): 642-645. 503 doi:10.1126/science.aao6868.

504 Beggs, S.E., Cardinale, M., Gowen, R.J., and Bartolino, V. 2014. Linking cod (Gadus morhua) 505 and climate: investigating variability in Irish Sea cod recruitment. Fish Oceanogr. 23: 54-64. 506 doi:10.1111/fog.12043.

507 Beverton, R.J.H., and Holt, S.J. 1957. On the dynamics of exploited fish populations. Great 508 Britain. Ministry of Agriculture, Fisheries and Food. Fishery investigations, Series 2, v.19. Her 509 Majesty's Stationery Office, London. 533 pp. 
510 Brander, K.M. 2010. Impacts of climate change on fisheries. J. Mar. Syst. 79(3): 389-402. doi:

$511 \quad 10.1016 /$ j.jmarsys.2008.12.015.

512 Bucholz, R.H., Tomkiewicz, J., Nyengaard, J.R., and Andersen, J.B. 2013. Oogenesis, fecundity

513 and condition of Baltic herring (Clupea harengus L.): A stereological study. Fish. Res. 145: 100-

514 113. doi:10.1016/j.fishres.2013.02.003.

515 Cardinale, M., Möllmann, C., Bartolino, V., Casini, B., Kornilovs, G., Raid, T., Margonski, P.,

516 Grzyb, A., Raitaniemi, J., Gröhsler, T., and Flinkman, J. 2009. Effect of environmental

517 variability of Baltic herring Clupea harengus populations. Mar. Ecol.:Prog. Ser. 388: 221-234.

518 doi:10.2495/ECO110061.

519 Casini, M., Bartolino, V., Molinero, J.C., and Kornilovs, G. 2010. Linking fisheries, trophic

520 interactions and climate: threshold dynamics drive herring Clupea harengus growth in the central

521 Baltic Sea. Mar. Ecol. Prog. Ser. 413: 241-252. doi:10.3354/meps08592.

522 Claireaux, M., dos Santos Schmidt, T. C., Olsen, E. M., Slotte, A., Varpe, Ø., Heino, M., and

523 Enberg, K. 2020. Eight decades of adaptive changes in herring reproductive investment: the joint

524 effect of environment and exploitation. ICES J. Mar. Sci. doi:10.1093/icesjms/fsaa123.

525 Cury, P.M., Fromentin, J.M. Figuet, S., and Bonhommeau. S. 2014. Resolving Hjort's dilemma:

526 How is recruitment related to spawning stock biomass in marine fish? Oceanography 27(4): 42-

527 47. doi:10.5670/oceanog.2014.85.

528 Dickey-Collas, M., Nash, R.D.M., Brunel, T., van Damme, C.J.G., Marshall, C.T., Payne, M.R.,

529 Corten, A., Geffen, A.J., Peck, M.A., Hatfield, E.M.C., Hintzen, N.T., Enberg, K., Kell, L.T., 
530 and Simmonds, E.J. 2010. Lessons learned from stock collapse and recovery of North Sea

531 herring: a review. ICES J. Mar. Sci. 67(9): 1875-1886. doi:10.1093/icesjms/fsq033.

532 dos Santos Schmidt, T. C., Slotte, A., Kennedy, J., Sundby, S., Johannessen, A., Óskarsson, G.

533 J., Kurita, Y., Stenseth, N. C., and Kjesbu, O. S. 2017. Oogenesis and reproductive investment of

534 Atlantic herring are functions of not only present but long-ago environmental influences as well.

535 Proc. Natl. Acad. Sci. 114(10): 2634-2639. doi:101073/pnas.1700349114.

536 Drinkwater, K. F., and Kristiansen, T. 2018. A synthesis of the ecosystem responses to the late

537 20th century cold period in the northern North Atlantic. ICES J. Mar. Sci. 75(7): 2325-2341.

538 doi:10.1093/icesjms/fsy077.

539 Glaser, S.M., Fogarty, M.J., Liu, H., Altman, I., Hsieh, C.H., Kaufman, L., MacCall, A.,

540 Rosenberg, A., Ye, H., and Sugihara, G. 2014. Complex dynamics may limit prediction in

541 marine fisheries. Fish Fish. 15: 616-633. doi:10.1111/faf.12037.

542 Garcia, T., Planque, B., Arneberg, P., Bogstad, B., Skagseth, O., and Tiedemann, M. 2021. An

543 appraisal of the drivers of Norwegian spring-spawning herring (Clupea harengus) recruitment.

544 Fish. Oceanogr. 30:159-173. doi:10.1111/fog.12510.

545 Haltuch, M.A., and Punt, A.E. 2011. The promises and pitfalls of including decadal scale climate

546 forcing of recruitment in groundfish stock assessment. Can. J. Fish. Aquat. Sci. 68(5): 912-926.

547 doi:10.1139/f2011-030. 
548 Hjort, J. 1914. Fluctuations in the great fisheries of northern Europe: viewed in the light of

549 scientific research. Rapports et Procès-Verbaux Conseil Permanent International pour

550 l'Exploration de la Mer 20: 1-228.

551 ICES. 2020. Baltic Fisheries Assessment Working Group (WGBFAS). ICES Sci. Rep. 2:45. 632

552 pp. doi:10.17895/ices.pub.6024.

553 Keyl, F., and Wolff, M. 2008. Environmental variability and fisheries: what can models do? Rev.

554 Fish Biol. Fish. 18(3): 273-299. doi:10.1007/s11160-007-9075-5.

555 Kirby, R., and Beaugrand, G. 2009 Trophic amplifications of climate warming. Proc. R. Soc. B.

556 276(1676): 4095-103. doi:10.1098/rspb.2009.1320.

557 Klais, R., Lehtiniemi, M., Rubene, G., Semenova, A., Margonski, P., Ikauniece, A., Simm, A.,

558 Põllumäe, A., Griniené, E., Mäkinen, K., and Ojaveer, H. 2016. Spatial and temporal variability

559 of zooplankton in a temperate semi-enclosed sea: implications for monitoring design and long-

560 term studies. J. Plankton Res. 38(3): 652-661. doi:10.1093/plankt/fbw022.

561 Klais, R., Otto, S., Teder, M., Simm, M., and Ojaveer, H. 2017. Winter-spring climate effects on

562 small-sized copepods in the coastal Baltic Sea. ICES J. Mar. Sci. 74(7): 1855-1864.

563 doi:10.1093/icesjms/fsx036.

564 Kornilovs, G., Möllmann, C., Sidrevics, L., and Berzinsh, V. 2004. Fish predation modified

565 climate-induced long-term trends of mesozooplankton in a semi-enclosed coastal gulf. ICES CM

566 2004/L:13. Copenhagen, Denmark. 26 pp. 
567 Kotta, J., Kotta, I., Simm, M., and Põllupüü, M. 2009. Separate and interactive effects of

568 eutrophication and climate variables on the ecosystem elements of the Gulf of Riga. Estuar.

569 Coast. Shelf Sci. 84(4): 509-518. doi:10.1016/j.ecss.2009.07.014.

570 Kotta, J., Lauringson, V., Martin, G., Simm, M., Kotta, I., Herkül, K., and Ojaveer, H. 2008.

571 Gulf of Riga and Pärnu Bay. In Ecology of Baltic Coastal Waters: Ecological Studies 197.

572 Edited by U, Schiewer. Springer, Berlin, pp. 217-243.

573 Köster, F. W., Huwer, B., Hinrichsen, H.-H., Neumann, V., Makarchouk, A., Eero, M., Dewitz,

574 B. V., Hüssy, K., Tomkiewicz, J., Margonski, P., Temming, A., Hermann, J.-P., Oesterwind, D.,

575 Dierking, J., Kotterba, P., and Plikshs, M. Eastern Baltic cod recruitment revisited-dynamics and

576 impacting factors. ICES J. Mar. Sci. 74: 3-19. doi:10.1093/icesjms/fsw172.

577 Le Bris, A., Pershing, A.J., Hernandez, C.M., Mills, K.E., and Sherwood, G.D. 2015. Modelling 578 the effects of variation in reproductive traits on fish population resilience. ICES J. Mar. Sci. 72: 579 2590-2599. doi:10.1093/icesjms/fsv154.

580 Leave-One-Out Cross-Validation. 2011. In Encyclopedia of Machine Learning. Edited by C.

581 Sammut and G.I. Webb. Springer, Boston, MA. doi:10.1007/978-0-387-30164-8_469.

582 Livdane, L., Putnis, I., Rubene, G., Elferts, D., and Ikauniece, A. 2016. Baltic herring prey

583 selectively on older copepodites of Eurytemora affinis and Limnocalanus macrurus in the Gulf

584 of Riga. Oceanologia 58(1): 46-53. doi:10.1016/j.oceano.2015.09.001. 
585 Margonski, P., Hansson, S., Tomczak, M.T., and Grzebielec, R. 2010. Climate influence on

586 Baltic cod, sprat, and herring stock-recruitment relationships. Prog. Oceanography 87(1-4): 277-

587 288. doi:10.1016/j.pocean.2010.08.003.

588 Marshall, C. T., Kjesbu, O. S., Yaragina, N. A., Solemdal, P., and Ulltang, O. 1998. Is spawner

589 biomass a sensitive measure of the reproductive and recruitment potential of Northeast Arctic

590 cod? Can. J. Fish. Aquat. Sci. 55(7): 1766-1783. doi:10.1139/f98-062.

591 Möllman, C., Kornilovs, G., and Sildrevics, L. 2000. Long-term dynamics of main

592 mesozooplankton species in the central Baltic Sea. J. Plank. Res. 22(11): 2015-2038.

593 doi:10.1093/plankt/22.11.2015.

594 Myers, R.A. 1998. When do environment-recruitment correlations work? Rev. Fish Biol. Fish. 8:

$595 \quad 285-305$.

596 Myers, R.A., and Barrowman, N.J. 1996. Is fish recruitment related to spawner abundance? Fish.

597 Bull. 94: 707-724.

598 Nash, R.D.M., and Dickey-Collas, M. 2005. The influence of life history dynamics and 599 environment on the determination of year class strength in North Sea herring (Clupea harengus

600 L.). Fish. Oceanogr. 14(4): 279-291. doi:10.1111/j.1365-2419.2005.00336.x.

601 Oeberst, R., Klenz, B., Gröhsler, T., Dickey-Collas, M., Nash, R.D.M, and Zimmermann, C.

602 2009. When is year-class strength determined in western Baltic herring? ICES J. Mar. Sci. 66:

603 1667-1672. 
604 Ojaveer, E. 1974. On the conditions determining the abundance of the Gulf of Riga spring and 605 autumn herring. Limnologisymposion 105-117.

606 Ojaveer, E., Arula, T., Lankov, A., and Shipilev, H. 2011. Impact of environmental deviations on 607 the larval and year-class abundances in the spring spawning herring (Clupea harengus membras 608 L.) of the Gulf of Riga (Baltic Sea) in 1947-2004. Fish. Res. 107: 159-168.

609 doi:10.1016/j.fishres.2010.11.001.

610 Ojaveer, H., Lankov, A., Lumberg, A., and Turovski, A. 1997. Forage fishes in the brackish Gulf 611 of Riga ecosystem (Baltic Sea). In Forage Fishes in Marine Ecosystems. Proceedings of the 612 International Symposium on the Role of Forage Fishes in Marine Ecosystems. University of 613 Alaska Fairbanks. Fairbanks, AK: 293-309.

614 Ojaveer, H., Lankov, A., Teder, M., Simm, M., and Klais, R. 2017. Feeding patterns of 615 dominating small pelagic fish in the Gulf of Riga, Baltic Sea. Hydrobiologia. 792: 331-344. 616 doi:10.1007/s10750-016-3071-5.

617 Ojaveer, E., Raid, T., and Suursaar, Ü. 2004. On the assessment and management of local 618 herring stocks in the Baltic Sea. In Management of shared fish stocks. Edited by A. Payne, C. 619 O'Brien, and S. Rogers. Blackwell Publishing, Oxford. pp. 240-250.

620 Oskarsson, G.J., and Taggart, C.T. 2010. Variation in reproductive potential and influence on 621 Icelandic herring recruitment. Fish. Oceanogr. 19: 412-426. doi:10.1111/j.1365-

622 2419.2010.00554.x. 
623 Ottersen, G., Stige, L.C., Durant, J.M., Chan, K.S., Rouyer, T.A., Drinkwater, K.F., and

624 Stenseth, N.C. 2013. Temporal shifts in recruitment dynamics of North Atlantic fish stocks:

625 effects of spawning stock and temperature. Mar. Ecol.: Prog. Ser. 480: 205-225.

626 doi:10.3354/meps10249.

627 Payne, M. R., Hatfield, E. M. C., Dickey-Collas, M., Falkenhaug, T., Gallego, A., Gröger, J.,

628 Licandro, P., Llope, M., Munk, P., Röckmann, C., Schmidt, J. O., and Nash, R. D. M. 2009.

629 Recruitment in a changing environment: the 2000s North Sea herring recruitment failure. ICES J.

630 Mar. Sci. 66: 272-277. doi:10.1093/icesjms/fsn211.

631 Perry, R.I., Cury, P., Brander, K., Jennings, S., Möllmann, C., and Planque, B. 2010. Sensitivity

632 of marine systems to climate and fishing: Concepts, issues and management responses. J. Mar.

633 Syst. 79(3-4): 427-435. doi:10.1016/j.jmarsys.2008.12.017.

634 Polte, P., Kotterba, P., Moll, D, and von Nordheim, L. 2017. Ontogenetic loops in habitat use

635 highlight the importance of littoral habitats for early life-stages of oceanic fishes in temperate

636 waters. Sci. Rep. 7: 42709. doi:10.1038/srep42709.

637 Putnis, I., Müller-Karulis, B., and Kornilovs, G. 2011. Changes in the reproductive success of the 638 Gulf of Riga herring. ICES Document CM 2011/H:13. 4 pp.

639 Radziejewska, T., and Chabior, M. 2004. Climatic and hydrological controls over the zoobenthos

640 in a southern Baltic coastal lagoon. Hydrobiologia 514(1): 171-181.

641 doi:10.1023/B:hydr.0000018217.38809.48. 
642 Raid, T., Kornilovs, G., Lankov, A., Nisumaa, A M., Shpilev, H., and Järvik, A. 2010.

643 Recruitment dynamics of the Gulf of Riga herring stock: density-dependent and environmental

644 effects. ICES J. Mar. Sci. 67: 1914-1920.

645 Rannak, L. 1971. On recruitment to the stock of spring herring in the northern Baltic. Rapports et

646 Procès-Verbaux des Réunions du Conseil International pour 1'Exploration de la Mer 160: 76-82.

647 Rannak, L., and Simm, M. 1979. Dependence of abundance of the Gulf of Riga spring herring

648 year-classes on the supply of larval food. ICES Baltic Fish Committee, C.M., J9. 1-10.

649 Ricker, W.E. 1954. Stock and recruitment. J. Fish. Res. Board Can. 11: 559-623.

650 Sigurdsson, T. 2006. The collapse of the Atlanto-Scandian herring fishery: Effects on the

651 Icelandic economy. In 13th International Institute of Fisheries Economics and Trade (IIFET)

652 Conference, July 11-14, Rebuilding Fisheries in an Uncertain Environment, Portsmouth, UK.

653 Skern-Mauritzen, M., Ottersen, G., Handegard, N.O., Huse, G., Dingsør, G.E., Stenseth, N.C.,

654 and Kjesbu, O.S. 2016. Ecosystem processes are rarely included in tactical fisheries

655 management. Fish Fish. 17: 165-175. doi:10.1111/faf.12111.

656 Solow, A. R. 2002 Fisheries recruitment and the North Atlantic Oscillation. Fish. Res. 54(2):

657 295-297. doi:10.1016/S0165-7836(00)00308-8.

658 Somarakis, S., Tsoukali, S., Giannoulaki, M., Schismenou, E., and Nikolioudakis, N. 2019.

659 Spawning stock, egg production and larval survival in relation to small pelagic fish recruitment.

660 Mar. Ecol.: Prog. Ser. 617-618: 113-136. doi:10.3354/meps 12642. 
661 Stige, L.C., Hunsicker, M.E., Bailey, K.M., Yaragina, N.A., and Hunt, G.L. Jr. 2013. Predicting

662 fish recruitment from juvenile abundance and environmental indices. Mar. Ecol.: Prog. Ser. 480:

663 245-261. doi:10.3354/meps10246.

664 Stige, L.C., Ottersen, G., Brander, K., Chan, K.S., and Stenseth, N.C. 2006. Cod and climate:

665 effect of the North Atlantic Oscillation on recruitment in the North Atlantic. Mar. Ecol.:Prog.

666 Ser. 325: 227-241.

667 Szuwalski, C.S., Vert-Pre, K.A., Punt, A.E., Branch, T.A., and Hilborn, R. 2015. Examining

668 common assumptions about recruitment: a meta-analysis of recruitment dynamics for worldwide

669 marine fisheries. Fish Fish. 16(4): 633-648. doi:10.1111/faf.12083.

670 Tiedemann, M., Nash, R. D. M., Stenevik, E. K., Stiasny, M. H., Slotte, A., and Kjesbu, O. S.

671 2020. Environmental influences on Norwegian spring-spawning herring (Clupea harengus L.)

672 larvae reveal recent constraints in recruitment success. ICES J. Mar. Sci.

673 doi:10.1093/icesjms/fsaa072.

674 Trochta, J. T., Branch, T. A., Shelton, A. O., and Hay, D. E. 2020 The highs and lows of herring:

675 A meta-analysis of patterns and factors in herring collapse and recovery. Fish Fish. 21(3):639-

676 662. doi:10.1111/faf.12452.

677 UNESCO. 1968. Zooplankton Sampling. Monographs on Oceanographic Methodology, vol. 2.

678 UNESCO Press, New York. 174 pp.

679 Walters, C.J., and Ludwig, D. 1981. Effects of measurement errors on the assessment of stock-

680 recruitment relationships. Can. J. Fish. Aquat. Sci. 38: 704-710. doi:10.1139/f81-093. 
681 Wilson, C.J., Murphy, H.M., Bourne, C., Pepin, P., and Robert, D. 2018. Feeding ecology of 682 autumn-spawned Atlantic herring (Clupea harengus) larvae in Trinity Bay, Newfoundland: is 683 recruitment linked to main prey availability? J. Plank. Res. 40(3): 255-258.

684 doi:10.1093/plankt/fby003.

685 Wood, S.N. 2017. Generalized Additive Models: An Introduction with R (2nd edition). Chapman 686 and Hall/CRC. 496 pp.

687 Xing, Q., Yu, H., Ito, S.-I., Ma, S., Yu, H., Wang, H., Tian, Y., Sun, P., Liu, Y., Li, J., and Ye, Z. 688 2021. Using a larval growth index to detect the environment-recruitment relationships and its 689 linkage with basin-scale climate variability: A case study for Japanese anchovy (Engraulis 690 japonicus) in the Yellow Sea. Ecol. Indic. 122: 107301. doi:10.1016/j.ecolind.2020.107301.

691 Zimmermann, F., Claireaux, M., and Enberg, K. 2019. Common trends in recruitment dynamics 692 of north-east Atlantic fish stocks and their links to environment, ecology and management. Fish 693 Fish. 20(3): 518-536. doi:10.1111/faf.12360.

694 Zimmermann, F., Enberg, K., and Mangel, M. 2021. Density-independent mortality at early life 695 stages increases the probability of overlooking an underlying stock-recruitment relationship.

696 ICES J. Mar. Sci. doi:10.1093/icesjms/fsaa246. 
698

699

700

701

702

703

704

705

706

707

708

709

710

711

712

713

714

715 predicted by the model (M2, see Table 2).

716 Fig. 4. Out of sample prediction for the Gulf of Riga herring recruitment abundance (R, $10^{6}$

717 individuals) during 1958-2015. For models and steps see Table 2. Black lines: observed R value;

718 grey lines: R value predicted with the given model. 
719 Fig. 5. Growing window analysis to test the changes in type (linear or non-linear), direction

720 (positive or negative) and strength $\left(\mathrm{R}^{2}\right)$ of the relationship between the Gulf of Riga spring

721 spawning herring recruitment abundance $(\mathrm{R})$ and $(\mathrm{a}-\mathrm{b})$ spawning stock biomass (SSB, thousand

722 tons), (c-d) abundance of E. affinis in open GoR (copepodites stages IV-V, $\ln \left(\right.$ ind. $\left.\mathrm{m}^{-2}\right)$ ), and (e-f)

723 winter severity (WS1, sum of negative daily temperatures, ${ }^{\circ} \mathrm{C}$ ). Left panel: type and the direction

724 of the relationships between $\mathrm{R}$ and the respective explanatory variable over increasing observation

725 period. Coloring of the lines indicates the number of years included in each step, corresponding to

726 the legend in panel c. Right panel: adjusted $\mathrm{R}^{2}$ values for each time-step, filled points denote values

727 where the step model was significant at $\mathrm{p}<0.05$.

728 Fig. 6. Sliding window analysis to test the stepwise changes in direction (positive or negative) and

729 strength $\left(\mathrm{R}^{2}\right)$ of the linear relationship between the Gulf of Riga spring spawning herring

730 recruitment abundance (R) and: (a-b) spawning stock biomass (SSB, thousand tons), (c-d)

731 abundance of E. affinis in open GoR (copepodites stages IV-V, $\ln \left(\right.$ ind. $\left.\mathrm{m}^{-2}\right)$ ), and (e-f) winter

732 severity (WS1, sum of negative daily temperatures, ${ }^{\circ} \mathrm{C}$ ). Left panel: slope of the linear model

733 (points) and mean value of the respective explanatory variable (grey line), fitted to each 15 year

734 subset of data. Error bars show the standard error of the slope for subsets where the slope was

735 significant at $\mathrm{p}<0.05$. Right panel: adjusted $\mathrm{R}^{2}$ of the linear model fitted in every step. Filled

736 points show steps where the model was significant at $\mathrm{p}<0.05$. 
Table 1. Statistical methods used in the study.

\section{Method Aim of the analysis}

GAM without interaction to Identify the set of variables that explain $\mathrm{R}$ the best, while

SSB (with forward selection) excluding SSB from the variables. Although R is expected

to depend on SSB, both $\mathrm{R}$ and SSB are recalculated and

corrected for several years after the observation year, hence

the model that includes SSB as predictor is less reliable in

the operational prediction of the R for current year. GAM

was chosen to test for the non-linearity of the relationships.

GAM including the interaction Identifying the set of variables that most likely affect R.

to SSB (with forward selection) SSB was only included as an interaction with other

variables due to the hypothesis that links between $\mathrm{R}$ and

environment are state-dependent, and the state itself is

defined by the level of SSB. GAM was chosen to test for the non-linearity of the links.

Out of sample prediction skill Evaluate the future R prediction skill of different model versions resulting from previous two analyses. Out of sample prediction skill is a generic validation procedure which provides more realistic evaluation of models' performance than the adjusted $\mathrm{R}^{2}$ of the model, and is often used as performance criteria for time series forecasts.

Growing window analysis Test if the shape of the link, direction or the strength of it 
Sliding window analysis changes when the longer period is analysed. The method is not common, i.e., we could not find any other study that would use a similar approach.

Test the changes in strength and direction of the links over time, while keeping the length of period fixed. Inspired by Kirby and Beaugrand (2009). 
Table 2. Results of the Generalized Additive Modelling of GoR herring recruitment abundance ( $\mathrm{R}, 10^{6}$ individuals) in 1958-2015, and the out of sample prediction skill of each model step. Explanatory variables tested in the analysis are SSB (thousand tons), winter severity (WS0, WS1; sum of negative daily temperatures, $\left.{ }^{\circ} \mathrm{C}\right)$, mean May air temperature $\left({ }^{\circ} \mathrm{C}\right)$, and abundance of E. affinis (copepodites stages I-III, IV-V, and adult copepods; $\ln \left(\right.$ ind. $\left.\mathrm{m}^{-2}\right)$ ) in the open GoR and Pärnu Bay, $\mathrm{n}=55$.

\begin{tabular}{llll}
\hline Model & Adjusted & P-value & Out of sample \\
& $\mathbf{R}^{2}$ & (for the first and & prediction skill, \\
& second variable, & adjusted $\mathbf{R}^{\mathbf{2}}$ \\
& respectively) & \\
\hline
\end{tabular}

Model 1 (M1; terms included individually without interaction to SSB)

\begin{tabular}{llll}
\hline Step 1: $\mathrm{R} \sim \mathrm{s}($ E. affinis (IV-V, GoR), & 0.46 & $<0.001$ & 0.40 \\
$\mathrm{k}=4)$ & &
\end{tabular}

Step 2 (final model): $\mathrm{R} \sim \mathrm{s}($ E. affinis $\quad 0.52 \quad<0.001 \quad 0.40$

$(\mathrm{IV}-\mathrm{V}, \mathrm{GoR}), \mathrm{k}=4)+\mathrm{s}($ winter $\quad 0.043$

severity (WS1), $\mathrm{k}=4$ )

\section{Model 2 (M2; all terms included in interaction with SSB)}

\begin{tabular}{|c|c|c|c|}
\hline Step 1: R $\sim$ te(SSB, E. affinis (IV-V, & 0.53 & $<0.001$ & 0.49 \\
\hline \multicolumn{4}{|l|}{ (GoR), $k=4)$} \\
\hline Step 2 (final model): R $\sim$ te(SSB, $E$. & 0.62 & $<0.001$ & 0.53 \\
\hline affinis (IV-V, GoR), k=4) + & & $<0.001$ & \\
\hline
\end{tabular}


te(SSB, winter severity

(WS1), $\mathrm{k}=4$ ) 


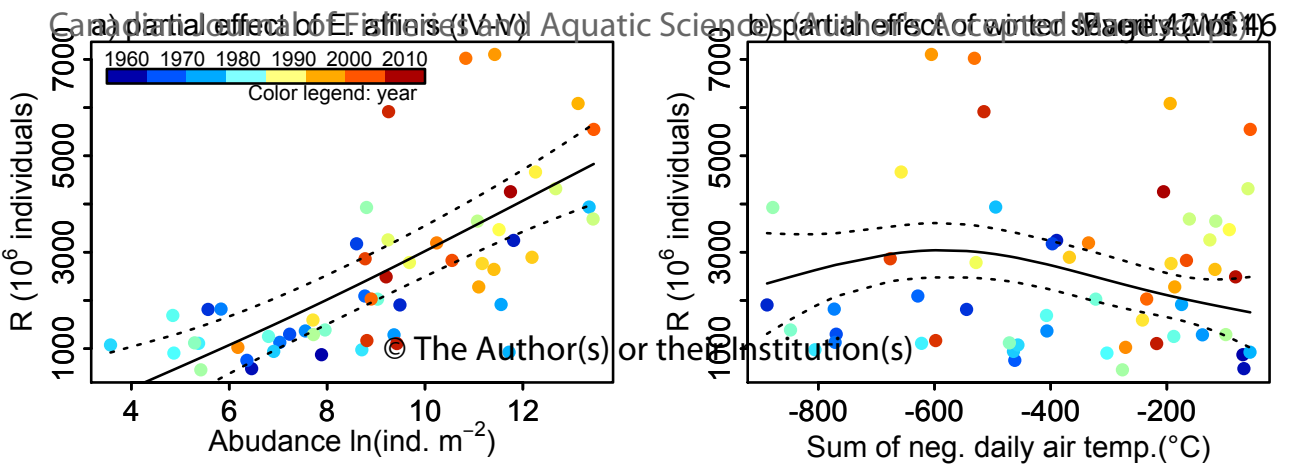




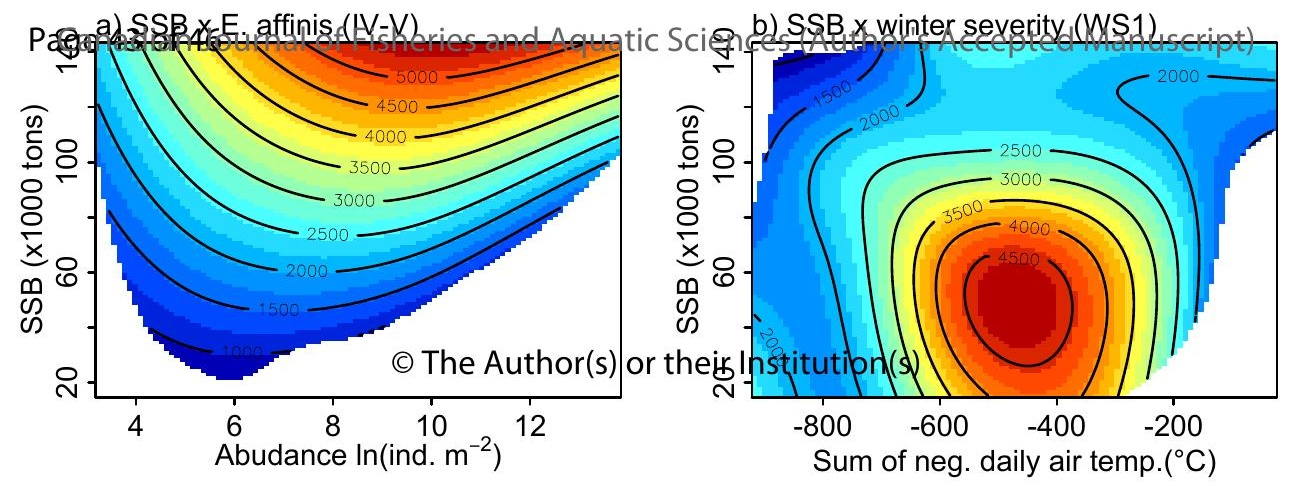



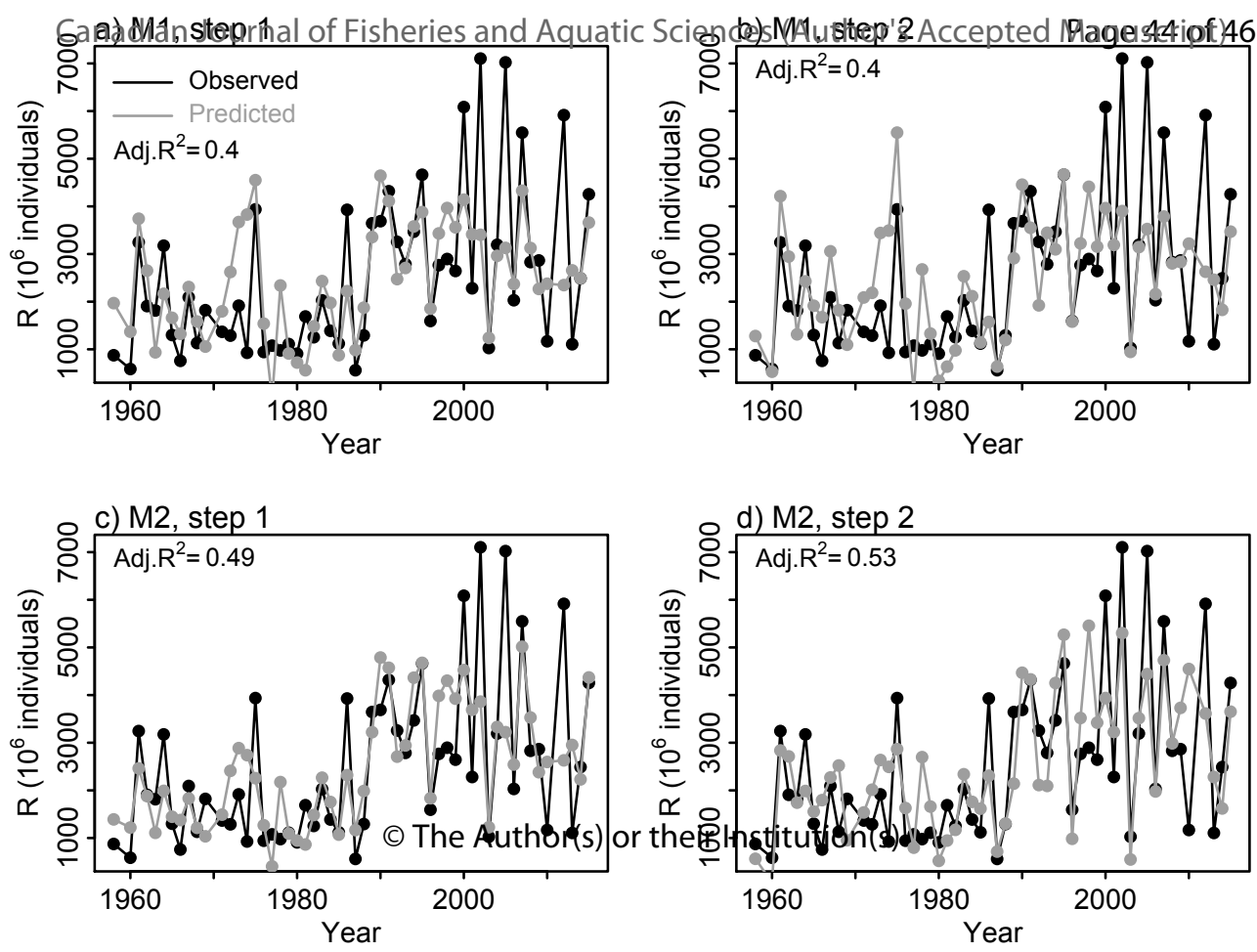
